\title{
Clinical experiences with a PEEK-based dynamic instrumentation device in lumbar spinal surgery: 2 years and no more
}

\author{
Stavros Oikonomidis ${ }^{1,2^{*}}$ (D) Ghazi Ashqar ${ }^{1}$, Thomas Kaulhausen ${ }^{1}$, Christian Herren ${ }^{3}$, Jan Siewe ${ }^{2}$ and Rolf Sobottke
}

\begin{abstract}
Background: Dynamic spine implants were developed to prevent adjacent segment degeneration (ASD) and adjacent segment disease (ASDi). Purpose of this study was to investigate the clinical and radiological outcomes of "topping off" devices following lumbar spinal fusion procedure using a PEEK-based dynamic rod system. Moreover, this study focused on the hypothesis that "topping off" devices can prevent ASD.

Methods: This prospective nonrandomized study included patients with indication for single-level lumbar fusion and radiological signs of ASD without instability. The exclusion criteria were previous lumbar spine surgery and no sign of disc degeneration in the adjacent segment according to magnetic resonance imaging. All patients were treated with single-level lumbar interbody fusion and dynamic stabilization of the cranial adjacent segment. Patients underwent a clinical examination and radiographs preoperatively and at 1 and 2 years after surgery. Analyses were performed on clinical data collected with the German Spine Registry using the core outcome measure index (COMI) and visual analogue scale (VAS) scores for back and leg pain.
\end{abstract}

Results: A total of 22 patients ( 6 male and 16 female) with an average age of 57.6 years were included in the study; 20 patients completed the follow-up (FU). The average COMI score was 9.0 preoperatively, 4.2 at the 1-year FU, and 4.7 at the 2-year FU. The average preoperative VAS scores for back and leg pain were 7.7 and 7.1, respectively. At the 1-year FU, the scores were 4.25 for back pain and 2.2 for leg pain, and at the 2-year FU, the scores were 4.7 for back pain and 2.3 for leg pain. At FU, failure of the dynamic topping off implant material was verified in four cases, and ASD of the segment cranial to the topping off was confirmed in three cases.

Conclusions: These results demonstrate significant improvements in clinical outcomes and pain reduction after lumbar spinal fusion with topping off at 2 years after surgery. However, the implant failed due to the high rate of implant failure and the development of ASD in the segment cranial to the dynamic stabilized segment.

Keywords: Topping off, Hybrid posterior fixation, Adjacent segment disease, Material failure, Hybrid lumbar instrumentation

\section{Background}

Lumbar and lumbosacral spinal fusion is a state of the art in lumbar spinal surgery for treating several degenerative disorders caused by changes in the lumbar spine (i.e., spinal disc herniation, lumbar spinal stenosis, and spondylolisthesis) [1, 2]. The well-known posterior rigid

\footnotetext{
* Correspondence: stavros.oikonomidis@uk-koeln.de

'Department of Orthopaedics and Trauma Surgery, Rhein-Maas Klinikum $\mathrm{GmbH}$, Mauerfeldchen 25, 52146 Wuerselen, Germany

${ }^{2}$ Department of Orthopaedics and Trauma Surgery, University Hospital

Cologne, Joseph-Stelzmann-Str. 24, 50931 Cologne, Germany

Full list of author information is available at the end of the article
}

pedicle screw fixation system offers initial stability, a high fusion rate, and good recovery of normal sagittal parameters in the lumbar spine. Stability is restored with surgical posterior fusion using pedicle screw and rod-based systems combined with an intervertebral cage following decompression (e.g., TLIF/PLIF technique). Furthermore, this procedure has been well documented in terms of its good and excellent long-term outcomes [3].

More recent research revealed that the stiffness caused by the posterior fusion operation often results in a redistribution of stress at the neighboring level, which leads

(C) The Author(s). 2018 Open Access This article is distributed under the terms of the Creative Commons Attribution 4.0 International License (http://creativecommons.org/licenses/by/4.0/), which permits unrestricted use, distribution, and 
to extended mobility and increased intradiscal pressure in the adjacent segments. These biomechanical changes can lead to new complications, such as adjacent segment degeneration (ASD) accompanied by facet hypertrophy, facet arthritis, and a higher risk of adjacent segment disease (ASDi) [4-7].

The general incidence of ASD varies from 5.2 to $18.5 \%$ at 2-5 years after lumbar fusion; however, Moreau et al. reported a rate $>20 \%$ for degenerative spondylolisthesis at 2 years after lumbar fusion $[8,9]$. Risk factors for the manifestation of ASD are being $>60$ years old, having an increased body mass index, preexisting disc and facet joint degeneration, the length of the fusion, and decreased postoperative lumbar lordosis in the sagittal alignment [10]. In the literature, the impact of ASD on clinical outcome is unclear [10]; however, ASDi may result in new clinical symptoms that are detectable adjacent to the previously fused segment.

Dynamic spine implants were developed to prevent ASD. These devices provide dynamic stabilization of the instrumented segment and, in focus to the adjacent segment, reduce load sharing and prevent hypermobility of the adjacent segment. Biomechanical studies reported a reduced range of motion (ROM) and load sharing of the adjacent segment when dynamic stabilization devices were used [11]. Khoueir et al. classified posterior dynamic stabilization devices into three groups: (1) interspinous spacer devices, (2) pedicle screw/rod-based devices, and (3) total facet replacement systems [12]. Many dynamic spine implants have been introduced in recent years, including purely dynamic or hybrid (semi-rigid) implants; however, it is uncertain whether patients benefit from these implants. Topping off systems provide dynamic stabilization for the segment cranially adjacent to the fusion.

The aim of this study was to assess the patient-dependent clinical and radiological outcomes within a 2-year follow-up (FU) period following lumbar interbody fusion using a dynamic instrumentation device to stabilize the segment superior to the rigid instrumented segment (topping off). Furthermore, this study also focused on the development of ASD in the segment superior to the dynamic instrumented level.

\section{Methods}

\section{Study design}

An observational prospective nonrandomized cohort study of patients with monosegmental degenerative alteration or spondylolisthesis of the lumbar spine and an indication for lumbar fusion was conducted (Table 1). Further inclusion criteria were radiological signs of degeneration without instability in the cranially adjacent segment (Pfirrmann grade 2-4) [13]. Detailed inclusion and exclusion criteria are listed in Table 1 [14]. Diagnosis was based on
Table 1 Inclusion and exclusion criteria

\begin{tabular}{ll}
\hline Inclusion criteria & Exclusion criteria \\
\hline - Indication for monosegmental & - No degeneration in the \\
lumbar spinal fusion with & segment cranial to the \\
osteochondrosis (Modic grades & segment intended for fusion \\
I-III) or spondylolisthesis & - Previous lumbar surgery \\
(Meyerding grades I-III) with & - Motor deficits \\
instability & - Scoliosis with a Cobb angle \\
- Radiological signs of degeneration & $>25^{\circ}$ \\
without instability in the level & - Spondylolisthesis (Meyerding \\
cranially adjacent to the intended & grade $>$ III) \\
fusion & - No prior history of metabolic \\
- Definition of adjacent segment & bone disease \\
degeneration using MRI (Pfirrmann & - No previous osteoporotic \\
grades II-IV) & fracture of the lumbar \\
& vertebrae \\
\hline
\end{tabular}

clinical and radiological examinations as well as magnetic resonance imaging (MRI). All patients underwent single-level lumbar interbody fusion using the transforaminal lumbar interbody fusion (TLIF) or posterior lumbar interbody fusion (PLIF) technique and additional dynamic instrumentation (topping off) of the segment superior to the rigid instrumented level according to segment pathology (Table 2). Three senior and "Master-certified" (German Spine Society) spinal surgeons performed the operations. Indications for lumbar spinal fusion were performed based on the radiological and clinical findings, and the Modic classification was used to characterize the grade of osteochondrosis [15].

\section{The implant}

The CD Horizon BalanC $C^{\mathrm{Tm}}$ (Medtronic Co., Minneapolis, USA) is a dynamic posterior pedicle screw/rod-based stabilization device, with the dynamic part of the rod constructed of polyether ether ketone (PEEK) and silicone ( $\varnothing$ 6.0; lordotic bend). The fusion portion is entirely made of PEEK (Fig 1). The silicon and PEEK hinge is designed to reduce stress on the adjacent level by restricting extreme ROM. The pedicle screws are made of standard titanium and are comparable to the screws used in the rigidly stabilized level.

\section{Data collection and outcomes}

Patients underwent clinical examinations and radiographs preoperatively and at 1 and 2 years after surgery. Evaluation of the clinical data was based on the German Spine Registry using the Core Outcome Measure Index (COMI) score, the Operation 2011 form, and a visual analogue scale (VAS) for back and leg pain. Data regarding length of hospital stay, operation time, perioperative and postoperative complications, blood loss, and ASA classification were collected by the German Spine Registry. Patients filled out the questionnaires (COMI and VAS) preoperatively and at the 1- and 2-year FU examinations.

The radiological examination contained X-rays of the lumbar spine in anterior-posterior and lateral views taken 
Table 2 Pathology of the index (fusion) and adjacent segment

\begin{tabular}{|c|c|c|}
\hline Cases & Pathology of the index segment & $\begin{array}{l}\text { Pathology of the adjacent } \\
\text { segment (Pfirrmann } \\
\text { classification) }\end{array}$ \\
\hline 1 & $\begin{array}{l}\text { Degenerative spondylolisthesis } \\
\|^{\circ} \text { L4-5 and absolute LSS }\end{array}$ & L3-4: grade III \\
\hline 2 & $\begin{array}{l}\text { Erosive osteochondrosis L5-S1 } \\
\text { Modic III and foraminal } \\
\text { stenosis L5 right }\end{array}$ & L4-5: grade II \\
\hline 3 & $\begin{array}{l}\text { Degenerative spondylolisthesis } \\
\|\|^{\circ} \text { L4-5 and absolute LSS }\end{array}$ & L3-4: grade II \\
\hline 4 & 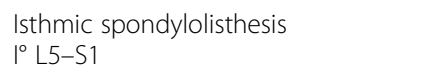 & L4-5: grade III \\
\hline 5 & $\begin{array}{l}\text { Erosive osteochondrosis L5-S1 } \\
\text { Modic III and absolute } \\
\text { LSS L5-S1 }\end{array}$ & L4-5: grade III \\
\hline 6 & $\begin{array}{l}\text { Degenerative spondylolisthesis } \\
\|^{\circ}\llcorner 4-5 \text { and erosive } \\
\text { osteochondrosis } L 4-5 \text { Modic } \|^{\circ}{ }^{\circ}\end{array}$ & L3-4: grade III \\
\hline 7 & Isthmic spondylolisthesis II L5-S1 & L4-5: grade III \\
\hline 8 & $\begin{array}{l}\text { Erosive osteochondrosis L5-S1 } \\
\text { Modic } 1 I^{\circ}\end{array}$ & L4-5: grade III \\
\hline 9 & $\begin{array}{l}\text { Degenerative spondylolisthesis } \\
\|^{\circ} \text { L4-5 with disc herniation }\end{array}$ & L3-4: grade II, LSS \\
\hline 10 & $\begin{array}{l}\text { Degenerative spondylolisthesis } \\
\|\|^{\circ}\llcorner 4-5\end{array}$ & L3-4: grade IV, LSS \\
\hline 11 & $\begin{array}{l}\text { Erosive osteochondrosis L4-5 } \\
\text { Modic III' and absolute LSS }\end{array}$ & L3-4: grade III, LSS \\
\hline 12 & $\begin{array}{l}\text { Erosive osteochondrosis L4-5 } \\
\text { Modic } 1 I^{\circ} \text { and absolute LSS }\end{array}$ & L3-4: grade IV \\
\hline 13 & $\begin{array}{l}\text { Degenerative spondylolisthesis } \|^{\circ} \text { L4- } \\
5 \text { and absolute LSS }\end{array}$ & L3-4: grade III \\
\hline 14 & $\begin{array}{l}\text { Degenerative spondylolisthesis } \|^{\circ}\llcorner 4- \\
\text { - }\end{array}$ & $\begin{array}{l}\text { L3-4: grade II, foraminal } \\
\text { stenosis bilateral }\end{array}$ \\
\hline 15 & $\begin{array}{l}\text { Erosive osteochondrosis L4-5 } \\
\text { Modic } \|^{\circ} \text { and absolute LSS }\end{array}$ & L3-4: grade II \\
\hline 16 & $\begin{array}{l}\text { Erosive osteochondrosis L5-S1 } \\
\text { Modic } 1 I^{\circ}\end{array}$ & L4-5: grade II \\
\hline 17 & $\begin{array}{l}\text { Degenerative spondylolisthesis } \\
\text { I }^{\circ} \text { L5-S1 and absolute LSS }\end{array}$ & L4-5: grade III \\
\hline 18 & $\begin{array}{l}\text { Degenerative spondylolisthesis } \\
\text { I }^{\circ} \text { L5-S1 }\end{array}$ & $\begin{array}{l}\text { L4-5: grade IV, } \\
\text { disc herniation }\end{array}$ \\
\hline 19 & $\begin{array}{l}\text { Degenerative spondylolisthesis } \\
\|^{\circ} \text { L4-5 and absolute LSS }\end{array}$ & L3-4: grade III \\
\hline 20 & $\begin{array}{l}\text { Erosive osteochondrosis L5-S1 } \\
\text { Modic III and absolute LSS }\end{array}$ & L4-5: grade III \\
\hline 21 & $\begin{array}{l}\text { Erosive osteochondrosis L5-S1 } \\
\text { Modic } 1 \mathrm{II}^{\circ} \text { and absolute LSS }\end{array}$ & L4-5: grade II \\
\hline 22 & 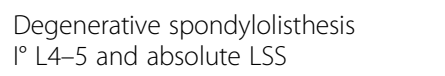 & $\begin{array}{l}\text { L3-4: grade III, } \\
\text { relative LSS }\end{array}$ \\
\hline
\end{tabular}

preoperatively and at 1 and 2 years after surgery. All $\mathrm{X}$-rays were performed in a standing position. Radiological signs of degeneration in the segment adjacent to the fusion (topping off segment) and the segment cranial to the topping off were recorded. Degeneration was categorized

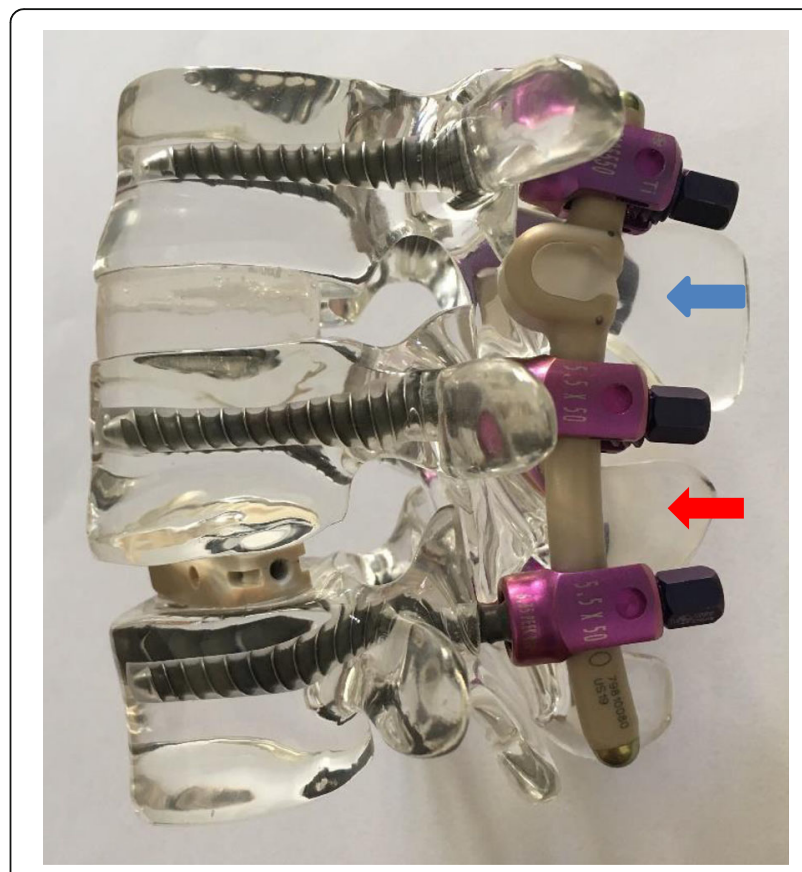

Fig. 1 CD Horizon BalanC $C^{\text {TM }}$. The dynamic section is composed of PEEK and silicon (blue marker), while the fusion section is composed of PEEK (red marker)

according to Weiner's classification [16], and a segment was classified as degenerated if it achieved a score of two or more.

Weiner's classification:

Radiographic scoring system for osteoarthritis of the lumbosacral spine:

Intervertebral disc:

$0=$ no disease. Defined by normal disc height, no spur formation, no eburnation, and no gas present.

$1=$ mild disease. Defined by $<25 \%$ disc-space narrowing, small spur formation, minimal eburnation, and no gas present.

2 = moderate disease. Defined by $25-75 \%$ disc-space narrowing, moderate spur formation, moderate eburnation, and no gas present.

3 = advanced disease. Defined by $>75 \%$ disc-space narrowing, large spur formation, marked eburnation, and gas present [16].

In addition, the pre- and postoperative sagittal parameters (e.g., the segmental endplate angle of the instrumentation and the topping off segment, lumbar lordosis, pelvic incidence, sacral slope, and pelvic tilt) were also compared.

\section{Statistical analysis}

SPSS (version 25, 76 Chicago, IL, USA) was used to evaluate the data. Descriptive and frequency analyses were used to describe the demographic data, clinical data, and outcomes. The COMI score and the radiological sagittal parameter were analyzed using 
Student's $t$ test for dependent samples, while the VAS scores for back and leg pain were analyzed using the Wilcoxon test. Line diagrams were used to depict the COMI and VAS scores as well as the radiological parameters, with whiskers indicating standard deviation. All reported $P$ values have a two-tailed significance level of alpha $=0.05$. No adjustment for multiple testing was performed.

\section{Results}

A total of 22 patients (16 female and 6 male) with symptomatic degenerative disease or spondylolisthesis of the lumbar spine met the inclusion criteria; 20 patients attended the FU examinations at 1 and 2 years after the procedure. The average age of the patients was $57.6 \pm 11.5$ (range 41-78) years at the time of surgery.

\section{Clinical data}

The average hospitalization time was $11.8 \pm 6.5$ (range 5-34) days. PLIF was performed in 18 cases, and TLIF was performed in four cases. Decompression by laminotomy and flavectomy was performed in the topping off (dynamic) segment in four cases. Clinical data are presented in Table 3.

\section{Clinical outcomes}

The average COMI and VAS scores preoperatively and at the 1- and 2-year FU are presented in Table 4. There was a significant reduction in the COMI score at the 1-year $(P$ $<0.001)$ and 2 -year $(P<0.001)$ FU compared to preoperatively. VAS scores for both back and leg pain significantly reduced at the 1 - and 2-year FU (back pain: $P=0.002$ at 1 year and $P=0.003$ at 2 years vs. preoperatively; leg pain: $P=0.001$ at 1 and 2 years vs. preoperatively). Figs. 2, 3,

Table 3 Clinical data

\begin{tabular}{|c|c|c|c|c|c|c|c|}
\hline Case & Operation & Age & Sex & $\begin{array}{l}\mathrm{BMl} \\
\left(\mathrm{kg} / \mathrm{m}^{2}\right)\end{array}$ & ASA & Operation time (h) & Intraoperative blood loss ( $\mathrm{mL})$ \\
\hline 1 & PLIF L4-5 with topping off L3-4 & 56 & $\mathrm{~F}$ & $26-30$ & 2 & $2-3$ & $100-500$ \\
\hline 2 & $\begin{array}{l}\text { TLIF L5-S1 right with topping off } \\
\text { L4-5 and foraminotomy L5 right }\end{array}$ & 50 & $\mathrm{~F}$ & $26-30$ & 2 & $2-3$ & $100-500$ \\
\hline 3 & PLIF $L 4-5$ with topping off $L 3-4$ & 65 & $\mathrm{~F}$ & $26-30$ & 2 & $2-3$ & $500-1000$ \\
\hline 4 & PLIF L5-S1 with topping off L4-5 & 66 & M & $20-25$ & 2 & $2-3$ & $500-1000$ \\
\hline 5 & TLIF L5-S1 left with topping off $L 4-5$ & 48 & $\mathrm{~F}$ & $31-35$ & 2 & $2-3$ & $500-1000$ \\
\hline 6 & PLIF $L 4-5$ with topping off $L 3-4$ & 56 & $\mathrm{~F}$ & $26-30$ & 2 & $3-4$ & $500-1000$ \\
\hline 7 & PLIF L5-S1 with topping off L4-5 & 50 & $\mathrm{~F}$ & $>35$ & 2 & $2-3$ & $100-500$ \\
\hline 8 & PLIF L5-S1 with topping off L4-5 & 50 & M & $20-25$ & 2 & $2-3$ & $100-500$ \\
\hline 9 & $\begin{array}{l}\text { PLIF } L 4-5 \text { with topping off } L 3-4 \text {, } \\
\text { flavectomy and laminotomy } L 3-4 \\
\text { bilateral }\end{array}$ & 72 & $\mathrm{~F}$ & $26-30$ & 2 & $3-4$ & $500-1000$ \\
\hline 10 & $\begin{array}{l}\text { TLIF } L 4-5 \text { left with topping off } L 3-4 \text {, } \\
\text { flavectomy and laminotomy } L 3-4 \text { left }\end{array}$ & 71 & $\mathrm{~F}$ & $31-35$ & 2 & $2-3$ & $1000-2000$ \\
\hline 11 & PLIF $L 4-5$ with topping off $L 3-4$ & 78 & M & $<20$ & 3 & $1-2$ & $500-1000$ \\
\hline 12 & PLIF $L 4-5$ with topping off $L 3-4$ & 43 & $\mathrm{~F}$ & $>35$ & 2 & $2-3$ & $100-500$ \\
\hline 13 & PLIF L4-5 with topping off L3-4 & 58 & M & $26-30$ & 2 & $3-4$ & $500-1000$ \\
\hline 14 & $\begin{array}{l}\text { PLIF } L 4-5 \text { with topping off } L 3-4 \text {, } \\
\text { laminotomy and foraminotomy } \\
\text { L3-4 bilateral }\end{array}$ & 61 & $\mathrm{~F}$ & $20-25$ & 2 & $2-3$ & $500-1000$ \\
\hline 15 & PLIF $L 4-5$ with topping off $L 3-4$ & 43 & M & $<20$ & 1 & $2-3$ & $100-500$ \\
\hline 16 & PLIF L5/S1 with topping off $L 4-5$ & 41 & M & $31-35$ & 2 & $2-3$ & $500-1000$ \\
\hline 17 & $\begin{array}{l}\text { PLIF } L 5-S 1 \text { with topping off } L 4-5 \text {, } \\
\text { laminotomy and flavectomy } L 3-4 \text { left }\end{array}$ & 64 & $\mathrm{~F}$ & $31-35$ & 3 & $3-4$ & $1000-2000$ \\
\hline 18 & $\begin{array}{l}\text { PLIF L5-S1 with topping off } L 4-5 \\
\text { and sequestrectomy } L 4-5 \text { left }\end{array}$ & 58 & $\mathrm{~F}$ & $<20$ & 1 & $2-3$ & $100-500$ \\
\hline 19 & PLIF $L 4-5$ with topping off $L 3-4$ & 71 & $\mathrm{~F}$ & $26-30$ & 3 & $3-4$ & $1000-2000$ \\
\hline 20 & TLIF L5-S1 right with topping off $L 4-5$ & 45 & $\mathrm{~F}$ & $20-25$ & 2 & $1-2$ & $100-500$ \\
\hline 21 & PLIF L5-S1 with topping off L4-5 & 45 & $\mathrm{~F}$ & $20-25$ & 2 & $2-3$ & $1000-2000$ \\
\hline 22 & PLIF $L 4-5$ with topping off $L 3-4$ & 76 & $\mathrm{~F}$ & $>35$ & 3 & $3-4$ & $500-1000$ \\
\hline
\end{tabular}


Table 4 Clinical outcomes: mean COMI score, mean VAS score for back pain, and mean VAS score for leg pain preoperatively and at the 1-year and 2-year FU

\begin{tabular}{llll}
\hline & Preoperatively & 1 -year FU & 2-year FU \\
\hline COMI score & $9.0 \pm 0.9$ (range & $4.2 \pm 2.5$ (range & $4.7 \pm 2.7$ (range \\
& $6.7-10.0$ ) & $0-7.5$ ) & $0.2-8.3$ ) \\
VAS back pain & $7.7 \pm 2.4$ (range & $4.25 \pm 2.4$ (range & $4.7 \pm 2.3$ (range \\
& $0-10)$ & $0-8)$ & $0-9$ ) \\
VAS leg pain & $7.1 \pm 2.9$ (range & $2.2 \pm 3.2$ (range & $2.3 \pm 2.35$ (range \\
& $0-10)$ & $0-8)$ & $0-8$ ) \\
\hline
\end{tabular}

and 4 illustrate the development of clinical outcomes during the FU.

\section{Radiological outcome}

The detailed radiological results of lumbar lordosis, the sagittal segmental endplate angle of the instrumentation, the sagittal segmental endplate angle of the dynamic segment, pelvic incidence, pelvic tilt, and sacral slope are presented in Table 5. Figs. 5 and 6 illustrate the development of the radiological parameters preoperatively, directly after the operation and during the FU.

Interestingly, a $2.2^{\circ}$ reduction in the mean sagittal segmental endplate angle of the dynamic segment was observed directly after surgery. The segmental kyphosis remained during the FU examinations. A reduction in the segmental lordosis of the dynamic segment could have a negative effect on the sagittal balance of the lumbar spine; however, no influence was observed in the development of lumbar lordosis. This reduction tended to be significant $(P=0.063)$. At the 2 -year $\mathrm{FU}$, there was a significant reduction $(P=0.044)$ of the sagittal segmental angle.

\section{Complications}

An incidental durotomy was documented as a perioperative complication in one case. Surgical postoperative complications were reported in three patients. One patient developed a lumbar radiculopathy without a neurological deficit. One patient needed revision surgery because of a misplaced pedicle screw. The pedicle screw misplacement was diagnosed after a computed tomography scan of the lumbar spine was performed due to a persistent radiculopathy without a neurological deficit. One case reported a superficial wound infection. A general complication of pulmonary disease (pneumonia) was reported in one case.

Obvious signs of material failure in the dynamic part of the implant were identified in four cases (18\%) (Figs. 7 and 8). In one of these cases, revision surgery was necessary due to persisting back pain during the FU visits (Fig. 9). The other three patients with material failure within the dynamic portion of the implant did not require any revision surgery due to a reduction in back pain and a sufficient clinical outcome.

In addition, radiological signs of ASD within the segment cranially adjacent to the dynamic instrumented segment were evident in three cases (15\%). These cases had a Weiner's grade of three (Fig. 10). The COMI scores in these three cases at the 2-year FU were 6.2, 1.15, and 1.6. The VAS scores for back pain were 2, 3, and 6, and the VAS scores for leg pain were 0,0 , and 1 . No cases of ASD were documented in the topping off segment.

\section{Discussion}

The development of ASDi has prompted the introduction of new operating methods, such as dynamic and semi-rigid implants, for the treatment of degenerative diseases and spondylolisthesis of the lumbar spine. These implants differ in terms of the materials used and the design and biomechanical properties of the dynamic section [12]. Dynamic spine implants allow mobility of the instrumented segment; however, some biomechanical studies have reported small differences in the mechanical performance of posterior dynamic and rigid implants [17].

Many studies reported adequate long-term clinical outcomes after posterior dynamic stabilization of the lumbar spine. In one retrospective study of 299 patients

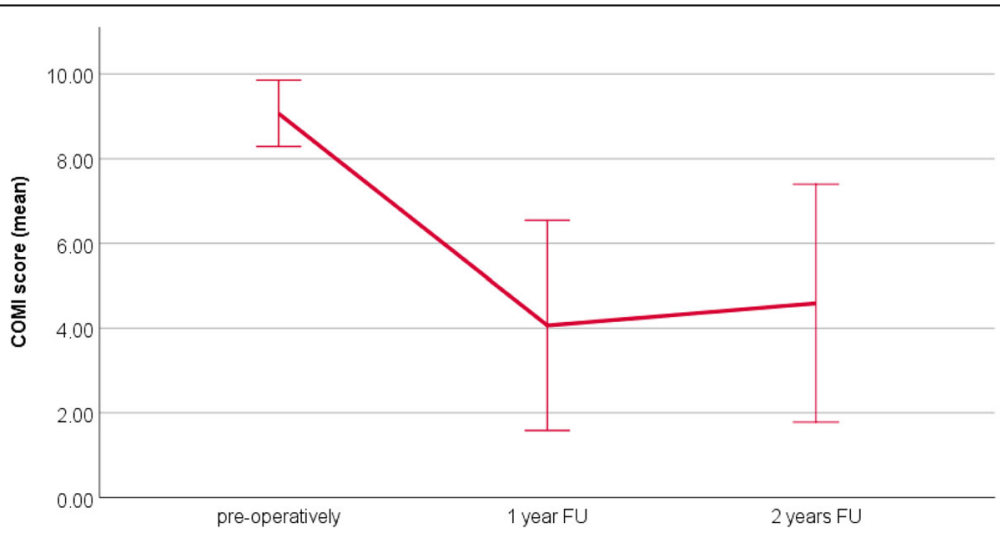

Fig. 2 The COMI score preoperatively and at the 1- and 2-year FU. The whiskers indicate the standard deviation. The COMI score is significantly improved at 1 and 2 years after surgery 


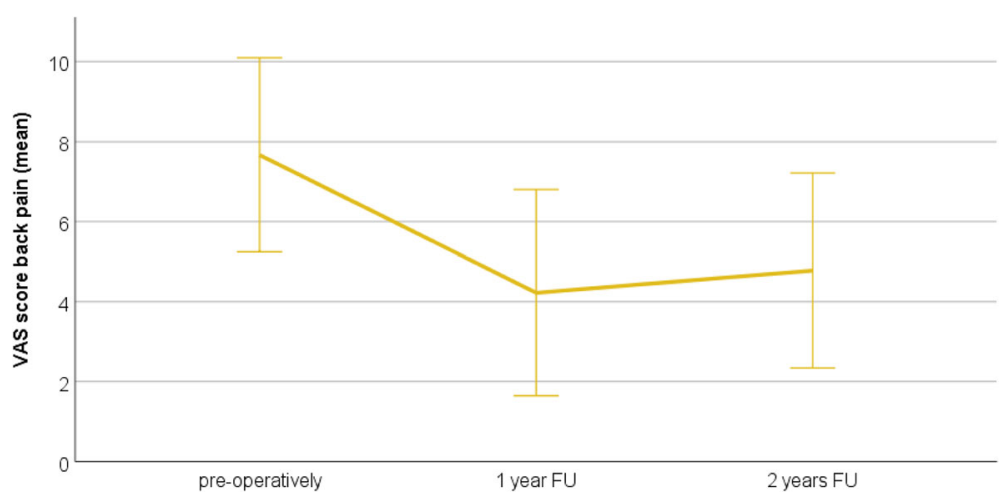

Fig. 3 The VAS score for back pain preoperatively and at the 1- and 2-year FU. The whiskers indicate the standard deviation. The VAS score for back pain is significantly improved at 1 and 2 years after surgery

with a mean FU of 9 months, Greiner-Perth et al. achieved good and stable clinical results using the DSS device (Paradigm Spine, LCC, New York, NY, USA) [18]. In a 2-year FU study of 20 patients treated with the Accuflex (Globus Medical, Inc.) posterior dynamic stabilization device, Reyes-Sanchez et al. reported improvements in pain and quality of life [19]. Overall, dynamic posterior stabilization devices appear to provide convincing clinical results [20,21]. Nonetheless, it remains uncertain whether dynamic posterior stabilization provides better results than traditional lumbar spinal fusion.

In addition, there is no convincing data regarding the hybrid posterior stabilization systems (topping off) during long-term FU [22]. The findings in this study indicate a significant reduction in back and leg pain as well as a significant improvement in clinical outcomes (according to COMI measurement) at 2 years after hybrid lumbar spine stabilization. These clinical results correlate with the outcomes of lumbar fusion and decompression that are summarized in the literature $[1,2]$.

However, the aim of this study was to examine whether the use of a hybrid lumbar spinal stabilization system and the resulting supplementary instrumentation of a segment offered any benefit to the patient. Hybrid posterior stabilization systems were developed to protect the adjacent segment from hypermobility after lumbar spinal fusion, as hypermobility of the adjacent segment can lead to ASDi $[23,24]$. Biomechanical studies examining hybrid dynamic lumbar stabilization reported reduced mobility of the adjacent segment after hybrid dynamic stabilization [11]. However, this precautionary fixation is not far from a two-level fusion [25]. This can lead to hypermobility of the segment adjacent to the dynamic stabilization $[11,26]$. Thus, ASD can occur in the next cranial segment, as was reported in this study. In this sense, hybrid posterior stabilization can lead to bisegmental fusion and patients underwent supplementary iatrogen operation morbidity.

One possible advantage of hybrid fusion versus single-level fusion is the option to perform extended decompression of the neural structures in the cranial segment and protect the segment from instability [27]. A long-term clinical study comparing single-level lumbar spinal fusion with hybrid lumbar spinal instrumentation identified no clinical benefits of hybrid fusion. In a prospective study comparing single-level fusion and hybrid

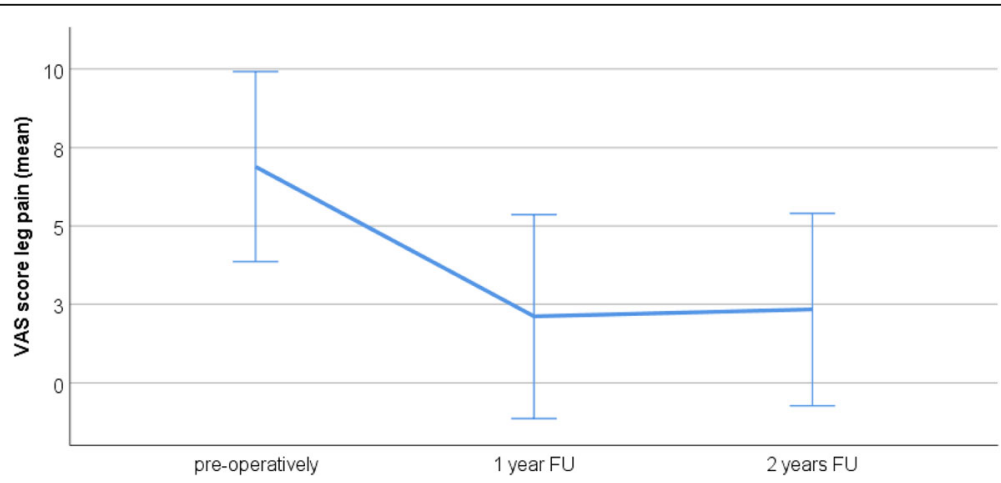

Fig. 4 The VAS score for leg pain preoperatively at the 1- and 2-year FU. The whiskers indicate the standard deviation. The VAS score for leg pain is significantly improved at 1 and 2 years after surgery 
Table 5 Radiological outcomes: directly after surgery, at 1-year and 2-year FU (* $=$ significant)

\begin{tabular}{|c|c|c|c|c|}
\hline & Preoperatively & Directly after surgery & 1-year FU & 2-year FU \\
\hline Lumbar lordosis $\left(^{\circ}\right)$ & $\begin{array}{l}-48.4 \pm-13.0 \text { (range } \\
-25.0 \text { to }-77.0)\end{array}$ & $\begin{array}{l}-48.0 \pm-9.9 \text { (range }-27.0 \\
\text { to }-73.0) P=0.886\end{array}$ & $\begin{array}{l}-50.6 \pm-11.2 \text { (range }- \\
27.0 \text { to }-73.0) P=0.562\end{array}$ & $\begin{array}{l}-49.6 \pm-10.4 \text { (range }-30.0 \\
\text { to }-65.0) P=0.835\end{array}$ \\
\hline Pelvic incidence $\left(^{\circ}\right)$ & $\begin{array}{l}63.8 \pm 11.8 \text { (range } \\
38.0-85.0 \text { ) }\end{array}$ & $\begin{array}{l}61.5 \pm 9.9 \text { (range } 38.0-85.0) \\
P=0.141\end{array}$ & $\begin{array}{l}63.4 \pm 7.5(\text { range } 51.0-72.0) \\
P=0.332\end{array}$ & $\begin{array}{l}63.3 \pm 9.5(\text { range } 40.0-76.0) \\
P=0.681\end{array}$ \\
\hline Pelvic tilt $\left({ }^{\circ}\right)$ & $\begin{array}{l}26.8 \pm 8.7 \text { (range } \\
10.0-40.0 \text { ) }\end{array}$ & $\begin{array}{l}26.8 \pm 8.7 \text { (range } 10.0-40.0) \\
P=0.561\end{array}$ & $\begin{array}{l}24.8 \pm 6.6(\text { range } 9.0-34.0) \\
P=0.018^{*}\end{array}$ & $\begin{array}{l}23.2 \pm 5.9(\text { range } 10.0-35.0) \\
P=0.027^{*}\end{array}$ \\
\hline Sacral slope $\left(^{\circ}\right)$ & $\begin{array}{l}37.3 \pm 9.6 \text { (range } \\
20.0-56.0 \text { ) }\end{array}$ & $\begin{array}{l}37.3 \pm 9.6(\text { range } 20.0-56.0) \\
P=0.329\end{array}$ & $\begin{array}{l}38.8 \pm 6.3(\text { range } 30.0-52.0) \\
P=0.244\end{array}$ & $\begin{array}{l}40.4 \pm 9.7 \text { (range } 23.0-58.0) \\
P=0.060\end{array}$ \\
\hline $\begin{array}{l}\text { Sagittal segmental endplate } \\
\text { angle of the instrumentation }\left(^{\circ}\right)\end{array}$ & $\begin{array}{l}-30.3 \pm-10.3 \text { (range } \\
-7.0 \text { to }-50.0)\end{array}$ & $\begin{array}{l}-31.3 \pm-5.2 \text { (range }-20.0 \\
\text { to }-40.0) P=0.949\end{array}$ & $\begin{array}{l}-31.1 \pm-7.6 \text { (range }-15.0 \\
\text { to }-46.0) P=0.609\end{array}$ & $\begin{array}{l}-31.1 \pm-7.0 \text { (range }-12.0 \\
\text { to }-43.0) P=0.622\end{array}$ \\
\hline $\begin{array}{l}\text { Sagittal segmental endplate } \\
\text { angle of the dynamic segment }\left({ }^{\circ}\right)\end{array}$ & $\begin{array}{l}-18.6 \pm-6.8 \text { (range } \\
-6.0 \text { to }-35.0)\end{array}$ & $\begin{array}{l}-16.4 \pm-5.0 \text { (range }-9.0 \\
\text { to }-30.0) P=0.063\end{array}$ & $\begin{array}{l}16.5 \pm-6.0 \text { (range }-7.0 \\
\text { to }-30.0) P=0.170\end{array}$ & $\begin{array}{l}-16.1 \pm-5.5 \text { (range }-10.0 \\
\text { to }-28.0) P=0.044^{*}\end{array}$ \\
\hline
\end{tabular}

instrumentation in the lumbar spine, Putzier et al. followed patients for 6 years and reported comparable functional outcomes. These authors used the Allospine Dynesys Transition device (Zimmer, Winterthur, Switzerland) [22]; however, biomechanical studies using Dynesys reported increased stiffness applied to the adjacent segment. Thus, Dynesys performs comparably to rigid implants [28, 29]. In a retrospective study, Baioni et al. assessed clinical and radiological outcomes after hybrid lumbar spinal fusion using the Dynesys implant. They reported satisfying clinical outcomes at the 5-year FU. In addition, the prevalence of radiographic ASD was 10\% (3/30 patients) [30]. In contrast, the results reported in our study show a radiographically detectable ASD rate of $15 \%$ within the segment superior to the dynamic instrumented level and, interestingly, no radiological or clinical signs of ASD or ASDi within the dynamic instrumented level. The prevalence of ASD in the segment cranially adjacent to the dynamic instrumented level (15\%) correlates with the incidence of ASD after lumbar spine fusion reported in the literature $[8,9]$. In this respect, the results show that hybrid lumbar spinal fusion using the $C D$ Horizon Balan $C^{\mathrm{rm}}$ rod system is not able to prevent the development of ASD. One possible reason for the development of ASD in the segment cranial to the dynamic instrumentation could be the reduction of lordosis of the dynamic instrumented segment affecting the sagittal balance of the lumbar spine. In our study, we reported a mean reduction of the sagittal endplate angle of the dynamic instrumentation of 2.2 .

In a retrospective study of 24 patients (mean FU of 8 months), Maserati et al. assessed clinical and radiological outcomes after hybrid lumbar instrumentation with the DTO. They found improvements in pain and symptomatic degeneration at the dynamically stabilized segment in one case and above the dynamically stabilized segment in two cases [31].

A biomechanical study examining the performance of the dynamic part of the $\mathrm{CD}$ Horizon BalanC $\mathrm{C}^{\mathrm{TM}}$ rod reported stiffness in the ROM (except for axial rotation) that was similar to that seen with rigid implants [25].

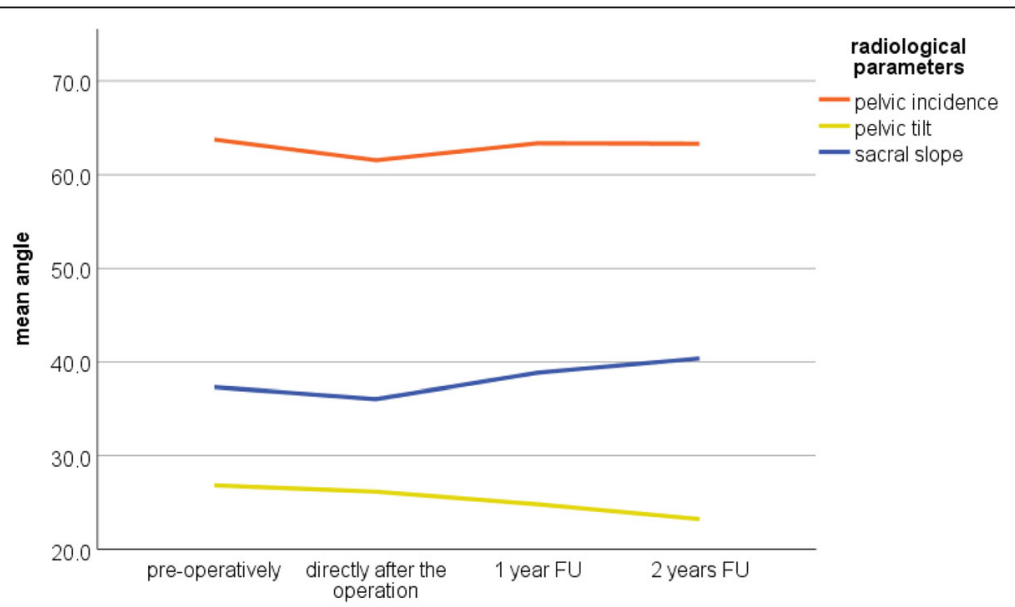

Fig. 5 The positive-valued radiological parameters preoperatively, directly after the operation at the 1- and 2-year FU. Pelvic incidence (PI; orange line), pelvic tilt (PT; yellow line), and sacral slope (SS; blue line). The figure shows a slight reduction in the PI after the operation $\left(2.3^{\circ}\right)$; however, this was comparable to the preoperative value at the 1-and 2-year FU 


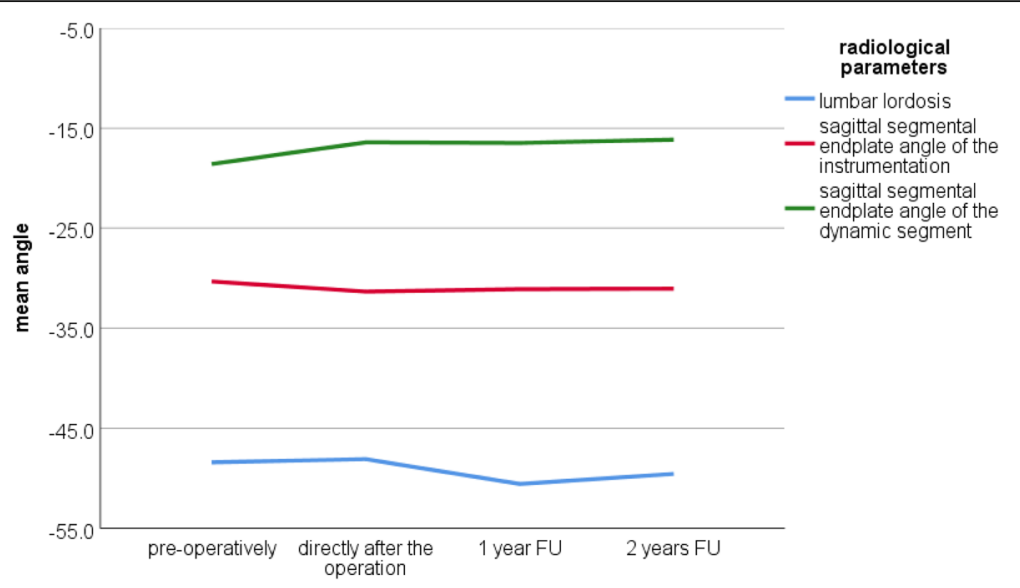

Fig. 6 The negative-valued radiological parameters preoperatively, directly after the operation and at the 1- and 2-year FU. Lumbar lordosis (LL; light blue), sagittal segmental endplate angle of the instrumentation (SSEl; purple line), and sagittal segmental endplate angle of the dynamic segment (SSED; green line). The mean SSED was reduced after the operation. The reduction in segmental lordosis remained during the follow-up. Mean SSEl increased slightly after the operation and remained during the follow-up

According to the radiological findings reported in this study, this biomechanical study supports the hypothesis that load sharing is transferred to one level above the instrumented segments. To the author's knowledge, there has been no published data regarding clinical outcomes after hybrid lumbar instrumentation with the CD Horizon BalanC $C^{\mathrm{Tm}}$ rod system. The dynamic part of the CD Horizon BalanC ${ }^{\mathrm{Tm}}$ rod is constructed of PEEK and silicone, making it different from the DTO. The results reported here show that there were significant improvements with regard to back and leg pain 2 years after surgery.

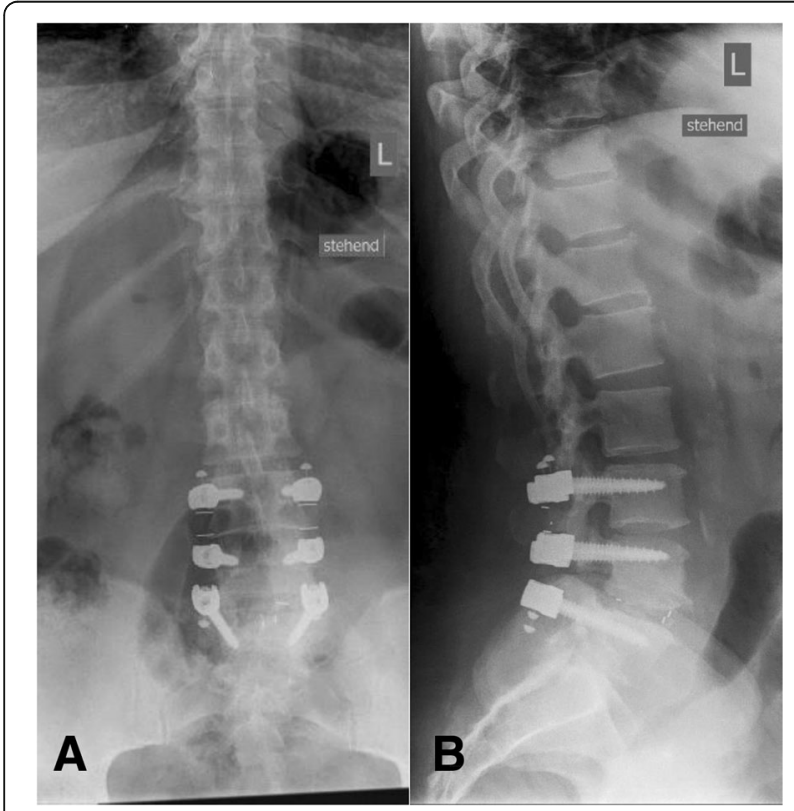

Fig. 7 Lumbar spine anterior-posterior (a) and lateral (b) radiographs immediately after surgery
The prevalence of material failure in the dynamic implant section was $18 \%$ in this study. In these cases, the adjacent segment was no longer protected by the topping off part of the implant. In the author's opinion, this high prevalence indicates a weak area of the implant. Material failure in other dynamic implants has also been reported [19, 32]; for example, Hoff et al. performed a prospective study over a 24-month period to compare single-level dynamic and hybrid instrumentation with the CD Horizon Agile spinal system (Medtronic, Memphis, TN, USA) and reported not only satisfactory functional outcomes but also a high failure

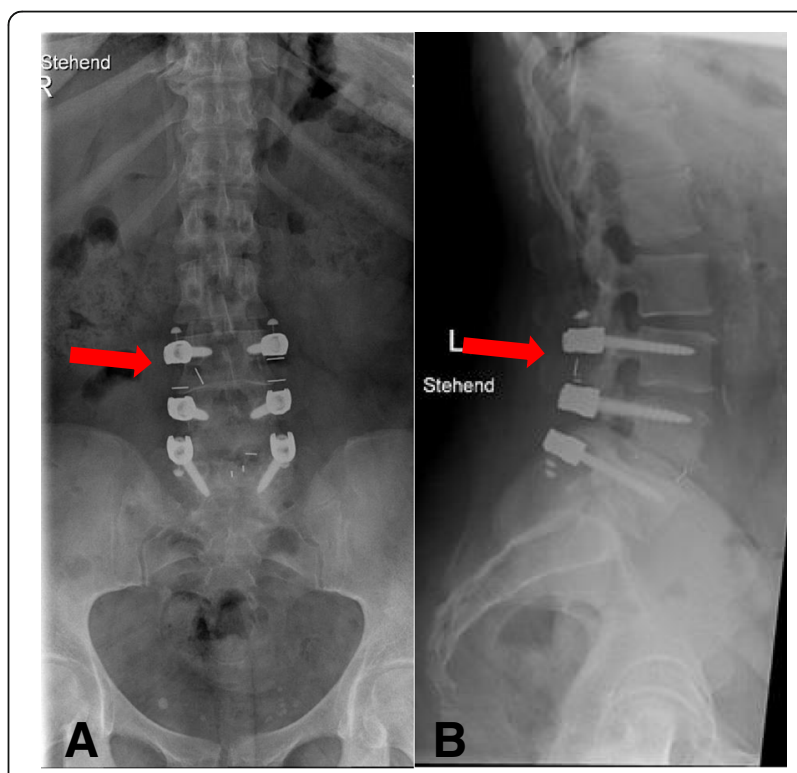

Fig. 8 Lumbar spine anterior-posterior (a) and lateral (b) radiographs at the 2-year FU. The red marker shows breakage of the PEEK and silicone C-shaped dynamic part at segment L3-4 


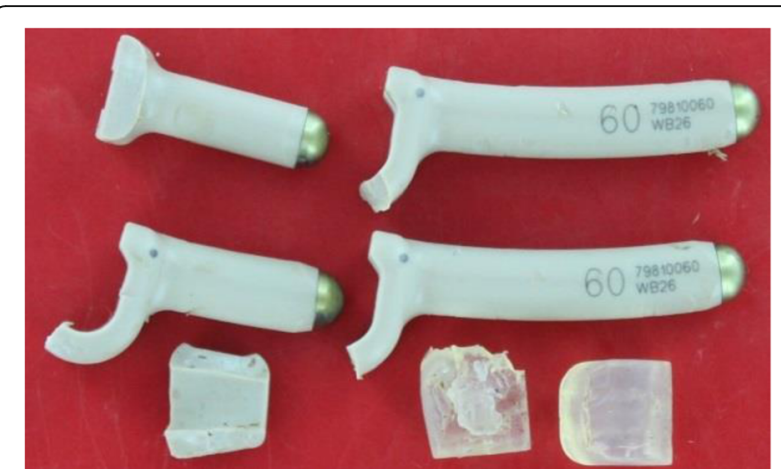

Fig. 9 A BalanC rod implant removed from a patient who required surgical revision due to back pain. Broken dynamic (PEEK and silicone) C-shaped part of both rods

rate of the dynamic portion of the implants [32]. Reports of material failure in dynamic spine implants raise concerns about the use of these devices. In addition, the reliability of before-market implant tests is questionable.

\section{Limitations}

First, there was no control group, and due to the fact that the data were obtained from patients who underwent surgery in a single center, there may also have been selection bias. Therefore, a further randomized controlled study should be conducted in multiple hospitals. Second, pathoanatomic risk factors (e.g., facet tropism and sagittalization and horizontalization of the lamina) were not observed.

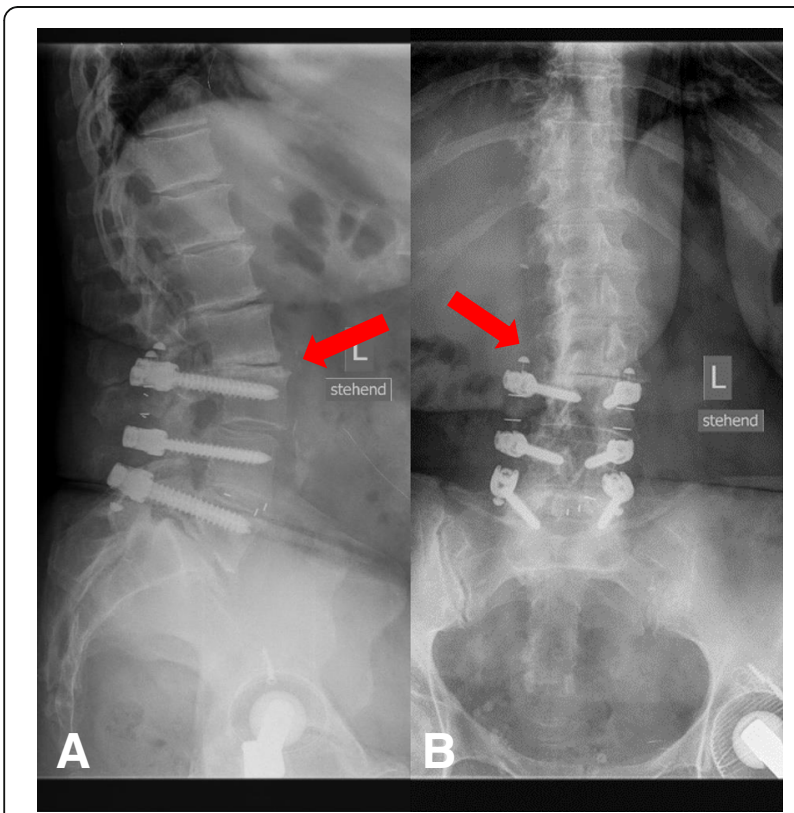

Fig. 10 Lumbar spine lateral (a) and anterior-posterior (b) radiographs at 2 years after surgery. Radiological signs of degeneration (red marker) in the segment cranially adjacent to the topping off segment

\section{Conclusion}

The high rate of material failure (18\%) and the onset of adjacent segment alteration superior to the dynamic instrumented level (15\%) suggests that the use of a "topping off" device is not able to reduce the incidence of ASD, whereas the reported pain decrease in the study correlates with the outcomes of lumbar fusion and decompression summarized in the literature $[1,2]$. Furthermore, the implant is obsolete due to the high failure rate. In this aspect, we conclude that supplementary dynamic instrumentation of the segment cranial to the rigid instrumentation does not offer any benefits to the patient.

\section{Abbreviations \\ ASA: American Society of Anesthesiologists; ASD: Adjacent segment degeneration; ASDi: Adjacent segment disease; COMl: Core outcome measure index; FU: Follow-up; LSS: Lumbar spinal stenosis; MRI: Magnetic resonance imaging; PEEK: Polyether ether ketone; PLIF: Posterior lumbar interbody fusion; ROM: Range of motion; TLIF: Transforaminal lumbar interbody fusion; VAS: Visual analogue scale}

\section{Availability of data and materials}

All data used and analyzed during this study are available from the corresponding author upon reasonable request.

\section{Authors' contributions}

SO contributed to the writing of the paper, searched for references, and collected and analyzed the data. GA and TK performed the surgeries. $\mathrm{CH}$ contributed to the writing of the paper and designed the study. JS contributed to the study design and data analysis. RS contributed to the study design, performed the surgeries, and performed data analysis. All authors reviewed and approved the final submitted version of the paper.

\section{Ethics approval and consent to participate}

The institutional review board of the German Spine Registry approved the study (2016448). All participants involved consented to participate in the study, and the written consent has been obtained from all participants.

\section{Consent for publication}

Written informed consent was obtained from all participants enrolled.

\section{Competing interests}

The authors declare that they have no competing interests.

\section{Publisher's Note}

Springer Nature remains neutral with regard to jurisdictional claims in published maps and institutional affiliations.

\section{Author details}

'Department of Orthopaedics and Trauma Surgery, Rhein-Maas Klinikum GmbH, Mauerfeldchen 25, 52146 Wuerselen, Germany. ${ }^{2}$ Department of Orthopaedics and Trauma Surgery, University Hospital Cologne, Joseph-Stelzmann-Str. 24, 50931 Cologne, Germany. ${ }^{3}$ Department of Trauma and Reconstructive Surgery, University Hospital RWTH Aachen, Pauwelsstraße 30, 52074 Aachen, Germany.

Received: 14 March 2018 Accepted: 2 August 2018

Published online: 09 August 2018

\section{References}

1. Fritzell P, Hägg O, Wessberg P, Nordwall A; Swedish Lumbar Spine Study Group. 2001 Volvo Award Winner in Clinical Studies: Lumbar fusion versus nonsurgical treatment for chronic low back pain: a multicenter randomized controlled trial from the Swedish Lumbar Spine Study Group. Spine (Phila Pa 1976). 2001;26(23):2521-2532; discussion 2532-4.

2. Mannion AF, Brox JI, Fairbank JC. Comparison of spinal fusion and nonoperative treatment in patients with chronic low back pain: long-term 
follow-up of three randomized controlled trials. Spine J. 2013;13(11):143848. https://doi.org/10.1016/j.spinee.2013.06.101.

3. Kim KT, Lee SH, Lee YH, Bae SC, Suk KS. Clinical outcomes of 3 fusion methods through the posterior approach in the lumbar spine. Spine (Phila Pa 1976). 2006;31(12):1351-7. discussion 1358

4. Chamoli U, Chen AS, Diwan AD. Interpedicular kinematics in an in vitro biomechanical assessment of a bilateral lumbar spondylolytic defect. Clin Biomech (Bristol, Avon). 2014;29(10):1108-15. https://doi.org/10.1016/j. clinbiomech.2014.10.002

5. Verma K, Gandhi SD, Maltenfort M, Albert TJ, Hilibrand AS, Vaccaro AR, Radcliff KE. Rate of adjacent segment disease in cervical disc arthroplasty versus single-level fusion: meta-analysis of prospective studies. Spine (Phila Pa 1976). 2013;38(26):2253-7. https://doi.org/10.1097/BRS. 0000000000000052.

6. Javedan SP, Dickman CA. Cause of adjacent-segment disease after spinal fusion. Lancet. 1999;354(9178):530-1.

7. Mannion AF, Leivseth G, Brox Jl, Fritzell P, Hägg O, Fairbank JC. ISSLS Prize winner: long-term follow-up suggests spinal fusion is associated with increased adjacent segment disc degeneration but without influence on clinical outcome: results of a combined follow-up from 4 randomized controlled trials. Spine (Phila Pa 1976). 2014;39(17):1373-83. https://doi.org/ 10.1097/BRS.0000000000000437.

8. Park P, Garton HJ, Gala VC, Hoff JT, McGillicuddy JE. Adjacent segment disease after lumbar or lumbosacral fusion: review of the literature. Spine (Phila Pa 1976). 2004;29(17):1938-44.

9. Moreau PE, Ferrero E, Riouallon G, Lenoir T, Guigui P. Radiologic adjacent segment degeneration 2 years after lumbar fusion for degenerative spondylolisthesis. Orthop Traumatol Surg Res. 2016;102(6):759-63. https:// doi.org/10.1016/j.otsr.2016.03.012

10. Chen BL, Wei FX, Ueyama K, Xie DH, Sannohe A, Liu SY. Adjacent segment degeneration after single-segment PLIF: the risk factor for degeneration and its impact on clinical outcomes. Eur Spine J. 2011;20(11):1946-50. https:// doi.org/10.1007/s00586-011-1888-1.

11. Mageswaran P, Techy F, Colbrunn RW, Bonner TF, McLain RF. Hybrid dynamic stabilization: a biomechanical assessment of adjacent and supraadjacent levels of the lumbar spine. J Neurosurg Spine. 2012;17(3):23242. https://doi.org/10.3171/2012.6.SPINE111054.

12. Khoueir P, Kim KA, Wang MY. Classification of posterior dynamic stabilization devices. Neurosurg Focus. 2007;22(1):E3.

13. Pfirrmann CW, Metzdorf A, Zanetti M, Hodler J, Boos N. Magnetic resonance classification of lumbar intervertebral disc degeneration. Spine (Phila Pa 1976). 2001;26(17):1873-8.

14. Siewe J, Bredow J, Oppermann J, Koy T, Delank S, Knoell P, Eysel P, Sobottke R, Zarghooni K, Röllinghoff M. Evaluation of efficacy of a new hybrid fusion device: a randomized, two-centre controlled trial. BMC Musculoskelet Disord. 2014;15:294. https://doi.org/10.1186/1471-2474-15-294.

15. Modic M, Masaryk T, Ross J, Carter J. Imaging of degenerative disk disease. Radiology. 1988;168(1):177-86.

16. Weiner DK, Distell B, Studenski S, Martinez S, Lomasney L, Bongiorni D. Does radiographic osteoarthritis correlate with flexibility of the lumbar spine? J Am Geriatr Soc. 1994;42(3):257-63.

17. Rohlmann A, Burra NK, Zander T, Bergmann G. Comparison of the effects of bilateral posterior dynamic and rigid fixation devices on the loads in the lumbar spine: a finite element analysis. Eur Spine J. 2007;16(8):1223-31.

18. Greiner-Perth R, Sellhast N, Perler G, Dietrich D, Staub LP, Röder C. Dynamic posterior stabilization for degenerative lumbar spine disease: a large consecutive case series with long-term follow-up by additional postal survey. Eur Spine J. 2016;25(8):2563-70. https:/doi.org/10.1007/s00586-016-4532-2.

19. Reyes-Sánchez A, Zárate-Kalfópulos B, Ramírez-Mora I, Rosales-Olivarez LM, Alpizar-Aguirre A, Sánchez-Bringas G. Posterior dynamic stabilization of the lumbar spine with the Accuflex rod system as a stand-alone device: experience in 20 patients with 2-year follow-up. Eur Spine J. 2010;19(12): 2164-70. https://doi.org/10.1007/s00586-010-1417-7.

20. Hoppe S, Schwarzenbach O, Aghayev E, Bonel H, Berlemann U. Long-term outcome after monosegmental $L 4 / 5$ stabilization for degenerative spondylolisthesis with the Dynesys device. Clin Spine Surg. 2016;29(2):72-7. https://doi.org/10.1097/BSD.0b013e318277ca7a.

21. Zhang Y, Shan JL, Liu XM, Li F, Guan K, Sun TS. Comparison of the Dynesys dynamic stabilization system and posterior lumbar interbody fusion for lumbar degenerative disease. PLoS One. 2016;11(1):e0148071. https://doi. org/10.1371/journal.pone.0148071.
22. Putzier M, Hoff E, Tohtz S, Gross C, Perka C, Strube P. Dynamic stabilization adjacent to single-level fusion: part II. No clinical benefit for asymptomatic, initially degenerated adjacent segments after 6 years follow-up. Eur Spine J. 2010:19(12):2181-9. https://doi.org/10.1007/s00586-010-1517-4.

23. Cheng BC, Gordon J, Cheng J, Welch WC. Immediate biomechanical effects of lumbar posterior dynamic stabilization above a circumferential fusion. Spine (Phila Pa 1976). 2007;32(23):2551-7.

24. Cakir B, Carazzo C, Schmidt R, Mattes T, Reichel H, Käfer W. Adjacent segment mobility after rigid and semirigid instrumentation of the lumbar spine. Spine (Phila Pa 1976). 2009;34(12):1287-91. https://doi.org/10.1097/ BRS.0b013e3181a136ab.

25. Herren C, Beckmann A, Meyer S, Pishnamaz M, Mundt M, Sobottke R, Prescher A, Stoffel M, Markert B, Kobbe P, Pape HC, Eysel P, Siewe J. Biomechanical testing of a PEEK-based dynamic instrumentation device in a lumbar spine model. Clin Biomech (Bristol, Avon). 2017;44:67-74. https://doi. org/10.1016/j.clinbiomech.2017.03.009.

26. Strube P, Tohtz S, Hoff E, Gross C, Perka C, Putzier M. Dynamic stabilization adjacent to single-level fusion: part I. Biomechanical effects on lumbar spinal motion. Eur Spine J. 2010;19(12):2171-80. https://doi.org/10.1007/ s00586-010-1549-9.

27. Schnake KJ, Schaeren S, Jeanneret B. Dynamic stabilization in addition to decompression for lumbar spinal stenosis with degenerative spondylolisthesis. Spine (Phila Pa 1976). 2006;31(4):442-9.

28. Stoll TM, Dubois G, Schwarzenbach $\mathrm{O}$. The dynamic neutralization system for the spine: a multi-center study of a novel non-fusion system. Eur Spine J. 2002;11(2):S170-8.

29. Schmoelz W, Huber JF, Nydegger T, Dipl-Ing CL, Wilke HJ. Dynamic stabilization of the lumbar spine and its effects on adjacent segments: an in vitro experiment. J Spinal Disord Tech. 2003;16(4):418-23.

30. Baioni A, Di Silvestre M, Greggi T, Vommaro F, Lolli F, Scarale A. Does hybrid fixation prevent junctional disease after posterior fusion for degenerative lumbar disorders? A minimum 5-year follow-up study. Eur Spine J. 2015; 24(7):855-64. https://doi.org/10.1007/s00586-015-4269-3.

31. Maserati MB, Tormenti MJ, Panczykowski DM, Bonfield CM, Gerszten PC. The use of a hybrid dynamic stabilization and fusion system in the lumbar spine: preliminary experience. Neurosurg Focus. 2010;28(6):E2. https://doi. org/10.3171/2010.3.FOCUS1055

32. Hoff E, Strube P, Rohlmann A, Gross C, Putzier M. Which radiographic parameters are linked to failure of a dynamic spinal implant? Clin Orthop Relat Res. 2012;470(7):1834-46. https://doi.org/10.1007/s11999-011-2200-8. 